\title{
Modulation of RNA polymerase processivity affects double-strand break repair in the presence of a DNA-end binding protein
}

Priya Sivaramakrishnan ${ }^{1,3 \dagger}$, Catherine C. Bradley ${ }^{1},{ }^{2 \dagger}$, Irina Artsimovitch ${ }^{4}$, Katelin M. Hagstrom ${ }^{1}$, Laura Deus Ramirez ${ }^{1}$, Xueyin Wen ${ }^{1,2}$, Matthew Cooke ${ }^{1}$, Maya Shaulsky ${ }^{1}$, Christophe Herman ${ }^{1,5,6 *}$, Jennifer A. Halliday $^{1 *}$

${ }^{1}$ Department of Molecular and Human Genetics, Baylor College of Medicine, Houston, TX, 77030, USA ${ }^{2}$ Medical Scientist Training Program, Baylor College of Medicine, Houston, TX, 77030, USA

Robert and Janice McNair Foundation/ McNair Medical Institute M.D./Ph.D. Scholars Program, Baylor College of Medicine, Houston, TX, 77030, USA

${ }^{3}$ Current address: Department of Genetics, University of Pennsylvania Perelman School of Medicine, Philadelphia, PA, 19104, USA

${ }^{4}$ Department of Microbiology, Ohio State University, Columbus, OH 43210, US

${ }^{5}$ Department of Virology and Microbiology, Baylor College of Medicine, Houston, TX, 77030, USA

${ }^{6}$ Dan L. Duncan Cancer Center, Baylor College of Medicine, Houston, TX, 77030, USA

* To whom correspondence should be addressed. Tel: 713-798-2126; Email: herman@bcm.edu halliday@bcm.edu

${ }^{\dagger}$ Equal contribution.

\section{ABSTRACT}

Homologous recombination (HR) is the predominant mechanism for double-strand DNA break repair in Escherichia coli, but recently non-homologous end joining (NHEJ) was described involving the Ku-like GAM protein of bacteriophage Mu (MuGam), sparking interest into its biology and utility as a model for a DNA-end binding protein. MuGam binds to DNA ends, but how it interferes with DNA repair enzymes or transcription in living cells remains elusive. In E. coli, RNA polymerase secondary channel interactors, such as DksA and GreA, have been shown to play a role in the coordination of transcription with DNA replication and break repair. Here we show that MuGam inhibits break repair by slowing down RecBCD resection and impeding HR in live bacteria. Loss of GreA restores DNA break repair in the presence of MuGam, in part by releasing MuGam from the DNA. Furthermore, using MuGam as a DNA break sensor, we found that DSBs are generated when translation is inhibited and more so in the presence of GreA supporting the model where uncoupling of transcription and translation increases transcription/replication collisions. Significantly, this work reveals that modulation of RNA polymerase processivity can impact DNA break repair in presence of a Ku-like protein. 


\section{INTRODUCTION}

Double strand DNA breaks (DSBs) are a lethal form of damage that can arise spontaneously as a byproduct of cellular growth and metabolism ${ }^{1}$. The two major pathways of DSB repair are homologous recombination (HR) or non-homologous end joining (NHEJ). All organisms that can perform NHEJ share a common feature - the presence of a Ku protein². The first step of NHEJ involves Ku binding to the ends of DSBs and recruiting enzymes to process the terminal ends of the break. This is followed by ligation of the processed ends to reestablish intact DNA. Escherichia coli does not have a Ku protein and lacks a canonical NHEJ pathway ${ }^{2,3}$. However, recently it was shown that the Gam protein from phage Mu (MuGam) can promote NHEJ-like ligation of DSB ends in E. coli when the bacterial ligase LigA is overexpressed, resulting in repair of broken ends ${ }^{4}$. This study raises questions about the role of MuGam in DSB repair and the utility of Gam as a model for Ku function in bacterial cells.

MuGam shares significant sequence and structural homology with eukaryotic $\mathrm{Ku}^{5}$. The main function of MuGam is to protect the phage's double-strand linear DNA from bacterial nucleases at various times during Mu's life cycle $e^{6,7}$. MuGam binds specifically to double-stranded DNA with blunt or protruding ends, but not to single-stranded DNA or RNA ${ }^{5}$. This feature of MuGam DNA binding has been exploited to visualize the ends of DSBs in E. coli and mammalian cells as well as to inhibit repair after CRISPR cutting $^{8-10}$. In E. coli, inducible expression of a MuGam GFP fusion (MuGam-GFP) outside of the context of phage infection allows both spontaneous and induced DSBs to be visualized at the single cell-single genomic locus level ${ }^{8}$. MuGam-GFP was able to detect both single- and double-ended DSBs in vivo. However, expression of MuGam phenocopies a deletion of $r e c B^{8}$. This was thought to be a consequence of MuGam hindering RecBCD access to double-strand DNA ends (DSEs), where this enzyme complex binds and processes repair intermediates ${ }^{11}$. The RecBCD complex is involved in HR-mediated repair of DSBs and salvage of broken replication forks ${ }^{12}$. RecBCD binds with high affinity to DSEs, resects or degrades DNA and loads the recombination protein RecA onto resected 3' ssDNA ${ }^{12}$. More recently, using single molecule tracking on assembled DNA curtains, Bhattacharyya et al. showed that MuGam does not block RecBCD binding to DSEs in vitro, but rather slows its exonuclease/helicase activity ${ }^{4}$. The extent of this slow down during RecBCD resection on genomic DNA in living bacterial cells is unknown. Furthermore, how the competition between MuGam and RecBCD binding to DSB ends can affect DSB repair outcomes, particularly by $\mathrm{HR}$, is also unclear.

DNA repair does not occur in isolation on the DNA template. In mammalian cells, mechanisms exist to silence local transcription upon DNA damage through chromatin remodeling ${ }^{13}$. These mechanisms likely evolved to reduce conflicts between RNAP and repair proteins - conflicts that also threaten bacterial cells. In E. coli, transcription-coupled repair (TCR) serves to recruit DNA repair proteins to RNA polymerase (RNAP) complexes stalled at helix-distorting and bulky lesions ${ }^{14}$. The stalled RNAPs are in 
turn removed by one of two helicases - Mfd (classical TCR) ${ }^{15}$ or UvrD in conjunction with the bacterial alarmone $\mathrm{ppGpp}^{16}$, allowing for repair enzymes to access the lesion. Another class of transcription factors that play an important role in orchestrating RNAP with DNA repair/replication conflicts, are the RNAP secondary channel interactors, GreA, GreB and DksA. The E. coli Gre factors stimulate the intrinsic cleavage activity of RNAP to generate a new 3' mRNA end, resetting the transcription elongation complex ${ }^{17,18}$. DksA functions during both transcription initiation and elongation and plays an important role in the maintenance of genome stability ${ }^{19-21}$. GreA was recently shown to impede DNA break repair by removing_backtracked RNAP complexes on DNA which can be seen as a signal for recombination ${ }^{22}$. On the other hand, DksA has been associated with many DNA repair processes such as preventing replication/transcription conflicts triggered during starvation, outcompeting GreA during DNA break repair and R-loop formation ${ }^{20,23,24}$.

In this study, we investigated how the presence of a DNA end binding protein, MuGam, impacts DNA break repair in vivo where other basic cellular processes co-occur on the same DNA template. We were interested in exploring whether MuGam bound to DNA ends would promote RNAP backtracking, and the consequences of this interaction on DSB repair.

\section{MATERIALS AND METHODS}

Bacterial strains, plasmids and growth conditions. Bacterial strains used in this study as listed in Table S1 and plasmids in Table S2. Bacteria were grown in LB/TB broth or on LB/TB agar plates at $37^{\circ} \mathrm{C}$. Antibiotics were added at the following concentrations when necessary - $30 \mu \mathrm{g} / \mathrm{ml}$ kanamycin (kan), 12.5 $\mu \mathrm{g} / \mathrm{ml}$ chloramphenicol (cam), $50 \mu \mathrm{g} / \mathrm{ml}$ carbenicillin (CB) and $3.3 \mu \mathrm{g} / \mathrm{ml}$ tetracycline (tet). Doxycycline (dox) was used at the concentrations indicated to induce MuGam expression from the $\mathrm{P}_{\mathrm{N} 25}$-tetO promoter $^{8} .0 .2 \%$ arabinose or $0.2 \%$ glucose were respectively added to induce or repress the I-Scel enzyme from the pBAD promoter. Cells were treated with phleomycin $(1.0 \mathrm{ug} / \mathrm{ml})$ to induced DSBs. Strain construction was performed using P1 bacteriophage transduction, as described by Miller ${ }^{25}$, and plasmid transformations were performed by electroporation, followed by appropriate selection ${ }^{26}$.

Survival assays. Semi-quantitative spot assays for viability were carried out by growing strains overnight in LB/TB (with antibiotics when appropriate), followed by diluting cultures and growing them until an absorbance $\left(\mathrm{OD}_{600}\right)$ of approximately 0.4 . The cultures were then serially diluted in $\mathrm{M} 9$ salts and $5 \mu$ of each dilution was spotted on LB/TB agar plates with and without the treatment to be tested. Quantitative plating efficiencies were determined by serially diluting overnight cultures and spreading appropriate dilutions on LB/TB agar plates (with and without indicated treatment). Colonies were counted after 48 hours. Percent survival was calculated as the number of colonies formed (CFU/ml) with treatment vs. without. 
Western blot of MuGam protein levels. Cell lysates were prepared by diluting overnight cultures 1:100 in LB-glucose $0.2 \%$ with $0,100,200$, or $400 \mathrm{ng} / \mathrm{mL}$ doxycycline and growing at $37^{\circ} \mathrm{C}$. After reaching $\mathrm{OD}_{600}$ of 0.1 , all treatments were further incubated for 1 hour. For each sample, $1.0 \mathrm{OD}_{600}$ of cells were pelleted, frozen at $-80^{\circ} \mathrm{C}$ to lyse, resuspended in $2 x$ loading buffer with $5 \%$ of $\beta$-mercaptoethanol, boiled at $100^{\circ} \mathrm{C}$. Samples were run on a $12 \%$ SDS-polyacrylamide gel and transferred to a 0.2 um PVDF membrane using the Trans-Blot Turbo Transfer system (BioRad). The blots were probed with 1:10,000 dilution of anti-rabbit GroEL (Guisbert et al., 2004) or 1:250 anti-mouse Gam ${ }^{8}$ and then probed with goat anti-rabbit (1:10,000 dilution; Invitrogen \#A-21244) or goat anti-mouse (1:3000; Invitrogen\# A-21236) secondary antibodies and analyzed for immunofluorescence. Blots were imaged (Azure 400, Azure Biosystems) and quantified using Image J.

Purification of MuGam protein. A bacterial strain containing polyhistidine-tagged MuGAM on an expression vector was grown at $32^{\circ} \mathrm{C}$ till log phase, after which the inducer Isopropyl $\beta-D-1$ thiogalactopyranoside (IPTG) was added and incubation continued for 2 hours. The protein was purified as described by Holzinger et al. with the modifications described as follows ${ }^{27}$. The sonication step was omitted, and cobalt was used to bind the his-tagged protein in a sepharose column. The column was washed with buffer multiple times with serially lowered urea concentrations, and finally the protein was eluted in $2 \mathrm{M}$ urea. Dialysis was performed to replace the urea-containing buffer with a solution containing potassium chloride, glycerol and dithiothreitol. MuGAM is a $21 \mathrm{kDa}$ protein. Both monomeric and dimeric forms of the protein were visible on a stained protein gel. Protein concentration was estimated by the standard Bradford assay.

In vitro assay for RNAP-Gam interaction. Purified biotin-tagged RNAP was bound to magnetic streptavidin coated beads and allowed to initiate transcription on a blunt-ended DNA template with P32 labeled 5' end, and then halted. MuGam protein (or without for control) was then added to the beads, followed by addition of missing nucleotides to allow the halted RNAP complex to complete transcription of the template DNA at $37^{\circ} \mathrm{C}$. At various times after resuming transcription, the contents were placed on a magnetic stand and the supernatant collected. The amount of DNA in the supernatant at each time was quantified by detection of P32 label. In experiments where GreB was included, the transcription factor was added and given enough time to bind at $37^{\circ} \mathrm{C}$ before the RNAP was released from halt.

XO-seq. XO-seq was performed as previously described ${ }^{22}$. TB media containing $100 \mathrm{ng} / \mathrm{mL}$ dox was inoculated $1: 100$ with overnight culture and grown at $37^{\circ} \mathrm{C}$ to an absorbance $\left(\mathrm{OD}_{600}\right) \sim 0.1$. After reaching logarithmic growth, the 0 hour samples were collected and $0.2 \%$ arabinose was added to induce I-Scel and cutting. Samples were collected 2 hours after arabinose induction and DNA isolation was performed using the Promega Wizard Genomic DNA Purification kit. The Nextera XT protocol and sample preparation kit was used to prepare libraries for sequencing and alignment on Illumina MiSeq. The 
resulting BAM files were loaded in Seqmonk software for further analysis. Reads were obtained by generating a set of running windows of $1 \mathrm{~kb}$ and a step size of the same length. Reads were corrected for the total read count to per million reads, counting duplicated reads once. In R, reads were log2transformed, normalized to paired 0 min controls, and graphed, as per the previously published XO-seq method $^{22}$.

MuGam-GFP foci analysis of dox treated cells. Cultures of the wild-type (WT) strain containing the dox-inducible MuGam construct were grown overnight at $32^{\circ} \mathrm{C}$ in LB media, diluted 1:100 into TB glucose $(0.2 \%)$ media and incubated shaking for $1 \mathrm{hr}$ at $37^{\circ} \mathrm{C}$ before treatment with $100 \mathrm{ng} / \mathrm{ml}$ anhydrotetracycline (ATC) plus either $0,100,200$ or $400 \mathrm{ng} / \mathrm{ml}$ dox for 24 hours for each experiment. After treatment cells were washed twice in $1 \times$ MinA salts, resuspended in $2 \%$ paraformaldehyde for 30 minutes on ice, then washed twice in $1 \mathrm{X}$ MinA salts and imaged. To follow cell growth and MuGam-GFP foci formation in vivo over time, 1\% TB glucose agar pads were prepared containing dox (400 ng/ml) using Gene Frames (Thermo Scientific \#AB-0577). Once the agar was set, the pad was cut in two sections and 2 ul of exponentially growing WT and $\triangle$ greA cells previously induced for MuGam-GFP expression overnight (100ng/ul of ATC) were placed on the individual sections of the pad, covered with a coverslip and growth of microcolonies $\left(35^{\circ} \mathrm{C}\right)$ was followed by time-lapse microscopy. Imaging was performed using a Zeiss HAL100 inverted fluorescence microscope. Fields were acquired at 100x magnification with an sCMOS camera (Photometrics). Bright field and fluorescence (EGFP cube=Chroma, \#41017; X-Cite120 fluorescence illuminator [EXFO Photonic Solutions]) images were acquired using Zen.1 (Zeiss) software. Foci analysis, cell counting, and cell length was determined using FIJI.

\section{RESULTS}

\section{MuGam induction is lethal in the presence of chronic DNA breaks}

The ability of MuGam to phenocopy DNA-end repair deficient cells ${ }^{8}$, in conjunction with its DNA endbinding properties ${ }^{5}$, suggests that MuGam confers cell toxicity by physically blocking access of the DNA end to repair proteins. Therefore, the effect of MuGam on DSB repair in vivo can be first assessed by measuring viability in the presence of DSB-inducing agents. To test this, we treated E. coli expressing MuGam from a doxycycline (dox)-inducible promoter with phleomycin (PHL), a drug known to induce DNA breaks (Fig. 1a, 1b). As previously observed, long-term induction of MuGam leads to a small decrease in viability (Fig. 1b) in wild-type (WT) E. coli. Phleomycin $(1 \mu \mathrm{g} / \mathrm{ml})$ treatment alone in WT cells leads to a 5fold loss in cell viability (Fig. 1b). In the presence of both phleomycin and MuGam, we observe a synergistic 4-log decrease in cell viability, suggesting that MuGam is severely toxic in the presence of DNA breaks likely due to an effective block of DNA repair function (Fig. 1b). 
$\mathrm{PHL}$ is a radiomemetic drug that creates DSBs at random positions in the genome. To determine if MuGam expression would be toxic when only a single DSB is created in the $E$. coli genome, we measured survival after DSB induction using an engineered recognition site for the I-Scel endonuclease at the lacA locus (Fig. 1c, 1d). I-Scel DSB induction at the lacA locus results in 100-fold loss of survival compared to WT strains lacking the enzyme ${ }^{22}$. When I-Scel cutting with MuGam expression is combined, we observe a 4-log decrease in cell viability compared with no MuGam or I-Scel induction (Fig. 1d,1e).

To confirm that expression of MuGam phenocopies loss of DNA break repair by the canonical HR pathway, $\triangle r e c B$ and $\triangle r e c A$ null mutations were introduced and tested in the I-Scel break model. In the presence of MuGam alone, viability of $\triangle \operatorname{rec} A$ or $\triangle r e c B$ bacteria were similar to WT (Fig. 1d,1e). Both $\triangle r e c A$ and $\triangle r e c B$ mutants were more sensitive to I-Scel induction alone, but only the $\triangle$ recA mutant showed significantly lower survival compared with WT in the presence of both MuGam and I-Scel (Fig. 1e). These results confirm that MuGam inhibits DSB-dependent DNA-end repair through HR.

Overall, the two break-induction methods provide complementary approaches to explore the complex processes that occur at DNA ends in presence of MuGam.

\section{MuGam toxicity is influenced by the RNAP secondary channel interactor, GreA}

We previously showed that removal of the transcription factor GreA, which rescues backtracked RNAP complexes (Fig. 2a), increases DSB repair activity upon phleomycin treatment or I-Scel break induction ${ }^{22}$. We wondered how the absence of GreA would affect DSBs in the presence of MuGam. We first measured cell viability in the presence of both MuGam and phleomycin in $\triangle$ greA mutants. The loss of viability observed in WT cells expressing MuGam and treated with phleomycin is almost completely rescued by the removal of GreA (Fig. 2b). This rescue by $\triangle g r e A$ is dependent on the canonical DSB resection pathway involving RecB (Fig. 2c). A simple explanation for this rescue by $\triangle g r e A$ could be that the absence of this auxiliary transcription factor decreases the levels of MuGam expression from the doxinducible promoter. To rule out this possibility, we performed a Western blot using a MuGam antibody and found no difference in protein levels between WT and the $\Delta g r e A$ cells (Fig. 2d).

To determine if the loss of viability upon MuGam induction could be affected by other RNAP secondary channel interactors, the functionally similar factor GreB was overexpressed in WT cells and the $\triangle g r e A$ mutant ${ }^{18,28}$. Expression of GreB from a high-copy plasmid abrogated the resistance of the $\triangle$ greA mutant to phleomycin with and without MuGam expression and further increased MuGam-associated toxicity observed in the WT strain (Fig. 2e). This suggests that both Gre factors can act similarly to promote MuGam-associated toxicity and is consistent with a shared function of GreA and GreB in stimulating 3' transcript cleavage to rescue RNAP backtracking ${ }^{28,29}$. 
We then used the I-Scel induced DSB condition to ensure that the phenotype of $\Delta g r e A$ extended beyond PHL-induced DSBs. In the I-Scel system, a milder but significant 4-fold rescue was observed upon MuGam induction in $\triangle g r e A$ bacteria exposed to continuous I-Scel cutting compared to a $\sim 6.5$-fold rescue without MuGam induction (Fig. 2f, $2 \mathrm{~g}$ ). As with PHL, the increased survival of the $\triangle$ greA strain to MuGam and I-Scel expression was dependent on $\operatorname{recB}$, suggesting involvement in the canonical RecBCDdependent recombinational repair pathway (Fg. 2f).

Bacterial Gre factors interact with RNAP via its secondary channel and stimulate nascent RNA cleavage in backtracked RNAP complexes thus promoting transcription elongation ${ }^{17,18,30}$ (Fig. 2a). DksA is another RNAP secondary channel interactor that acts as a transcription initiation factor and an elongation factor in living bacterial cells ${ }^{19,23}$. We previously described a mechanism where competition between DksA and GreA for RNAP binding influences transcription-DNA break repair conflicts ${ }^{22}$. However, DksA likely has additional roles in DNA repair, which might depend on the type of lesion and damaging agent ${ }^{21}$. The $\triangle d k s A$ strain was much more sensitive to MuGam expression with I-Scel DSB induction than WT cells (Fig. 2g). The $\triangle d k s A \Delta g r e A$ double mutant had a phenotype similar to the $\triangle g r e A$ mutant (Fig. $2 \mathrm{~g}$ ). These results are consistent with the competition of GreA and DksA for the secondary channel, where we would expect increased GreA activity in $\triangle d k s A$ strains causing reduced survival, but equal rescue for $\triangle d k s A \Delta g r e A$ and $\triangle g r e A$ mutants.

Altogether, these results suggest that modulation of RNAP by secondary channel interactors affects the activity of MuGam at DNA breaks.

\section{DNA resection at DSBs is altered by MuGAM expression}

We next looked at the pattern of DNA resection during break repair in presence of MuGam to examine repair kinetics in live bacteria. DSB repair in E. coli proceeds through dynamic intermediates of RecBCDdriven DNA resection and RecA-mediated recombinational repair ${ }^{12,31}$. Capturing these intermediates in vivo has historically been a technical hurdle for the DNA repair field - a problem which XO-seq was developed to address ${ }^{22}$. In XO-seq, following induction of a DSB, resection at the breakpoint locally depletes sequencing coverage, which is then reconstituted by recombination-mediated DNA synthesis. By graphing read counts across cutsite-proximal loci, it is possible to visualize the average of resection and recombination activity. In WT cells, read loss after I-Scel cutting at the lacA locus is asymmetrical around the break site, extending less than $100 \mathrm{~Kb}$ on the origin-proximal direction, but more than $200 \mathrm{~Kb}$ in the origin-distal side of the break (Fig. 3a). This asymmetry can be attributed to the different distribution of active Chi sites upstream and downstream of the cut-site ${ }^{12,22}$. 
To study the role of MuGam on DNA resection during DSB repair, we performed XO-seq after inducing DSBs at lacA in cells expressing MuGam. Under these conditions, we observed a read constriction in the DNA degradation pattern around the cutsite compared to WT cells not expressing MuGam (Fig. 3a). A deeper canyon of $20 \mathrm{~Kb}$ around the break is formed in presence of MuGam in comparison to no MuGam, likely due to the inability of cells to repair the DNA break (Fig. 3a).

To determine if RecBCD is responsible for the resection around the break, we performed a similar experiment in a $\triangle r e c B$ mutant. In the absence of MuGam binding, degradation in $\triangle r e c B$ cells is more extensive compared to WT cells (Fig. 3a, 3b), likely due to resection by other exonucleases such as RecJ ${ }^{22}$. When MuGam is expressed in $\triangle r e c B$ cells, strikingly, no DNA degradation around the cutsite was observed upon break induction (Fig. 3b, 3c). The lack of MuGam-associated resection in the $\Delta r e c B$ mutant suggests that MuGam-bound ends are not a substrate for resection by other bacterial exonucleases. These data lend further support to a model where RecBCD can process DNA ends in the presence of MuGam, albeit at a much-reduced efficiency ${ }^{4}$. Importantly, while $\Delta r e c B$ bacteria were protected from resection in the presence of MuGam, this did not translate to enhanced survival over WT cells (Fig. 2f).

To explore how the slow-down of resection by MuGam in turn affects RecA loading, we next performed XO-seq in $\triangle r e c A$ cells. Without MuGam, $\triangle r e c A$ cells display a massive DNA degradation extending over $1 \mathrm{Mb}$ downstream of the I-Scel site (Fig. 3d)22. In the presence of MuGam, DNA degradation was significantly impeded in $\triangle r e c A$, and was even lower than in WT cells with MuGam (Fig. 3e). This supports the model proposed by Battacharya et al. in which MuGam, can slow down RecBCD resection, and even in the absence of RecA to promote recombination, further degradation of DNA is still prevented.

To investigate the mechanism by which loss of GreA promotes DSB repair at MuGam-bound DNA ends, we performed XO-seq in the $\triangle$ greA mutant and observed a significant increase in degradation compared with WT cells (Fig. $3 \mathrm{~g}$ ). This suggests that the presence of GreA slows resection only when MuGam is present. In the absence of MuGam however, $\triangle$ greA cells show reduced resection as has been previously reported (Fig. 3f) $)^{22}$.

\section{RNAP stimulates MuGam dissociation in the absence of GreA in vitro}

Based on the above results, we hypothesize that when an RNAP complex encounters MuGam in the absence of GreA, it is capable of displacing the end-binding protein from the DNA. To test this, we performed in vitro experiments with purified MuGam. Transcription was initiated on a labelled DNA template using biotin-tagged RNAP and halted. MuGam was then added and transcription was allowed to restart by supplementing the reaction with 'chase' nucleotides. At several time intervals after transcription 
resumption, the reaction was moved to a magnetic stand. As the interaction between biotin-tagged RNAP and streptavidin magnetic beads pellets the RNAP, the amount of free DNA in the supernatant determines the extent of RNAP dissociation from template DNA (Fig. 4a). In the absence of any auxiliary transcription factors, dissociation of RNAP from DNA decreased over time when MuGam was added (Fig. $4 b)$. This suggests that the presence of MuGam prevents RNAP removal from the DNA end, perhaps due to the formation of an arrested complex. Without MuGam, the level of RNAP dissociation from the DNA was similar, irrespective of the presence of GreB (Fig. 4c). However, when both MuGam and GreB were present in the reaction, more RNAP was retained on the DNA (Fig. 4d). The rescue of backtracked RNAP by $G r e B$ requires two acidic amino acids present at the tip of the $N$ terminus of the protein ${ }^{28}$. One of these residues, aspartic acid 41 , when mutated to asparagine impairs the ability of GreB to cleave RNA displaced due to backtracking ${ }^{28}$. The GreB D41N protein is thus unable to revive backtracked complexes. The amount of RNAP that remained bound to DNA over time was similar when no accessory transcription factor was present compared with the reaction supplemented with the GreBD41N mutant protein (Fig. 4d). Since reduced RNAP dissociation stimulated by GreB was only observed when MuGam was bound to DNA, and the effect was abrogated when the anti-backtracking activity of GreB was impaired, we conclude that RNAP backtracks when it encounters MuGam bound to DNA (Fig. 4e). Without Gre factors present to reverse backtracking, RNAP dissociation is increased possibly evicting Gam and allowing for DSB repair to ensue. In the presence of Gre, a futile cycle of transcription restart and hitting a MuGam roadblock could potentially inhibit DSB repair (Fig. 4e).

\section{Sub inhibitory concentration of doxycycline induces DNA breaks.}

The expression of a GFP tagged-MuGam under the doxycycline (dox) promoter has been previously used to quantify levels of spontaneous and induced DSBs in E.coli, which are visualized as GFP foci at the break site ${ }^{8}$. During the course of this work, we noticed that a higher concentration of dox $(200 \mathrm{ng} / \mathrm{ml})$ used to induce MuGam expression, dramatically reduced viability in WT cells but had no effect on viability in strains not containing the dox-inducible MuGam (Fig. 5a). We also observed that this additive dox and MuGam-mediated toxicity is almost completely suppressed by the removal of GreA (Fig. 5a). Westernblot analysis suggests that levels of MuGam protein were not increased at higher concentrations of dox (200 ng/ml, $400 \mathrm{ng} / \mathrm{ml}$ ) (Supplemental figure 1a), suggesting in conjunction with MuGam, dox itself is somehow inducing DSBs at higher doses. To visualize DNA break formation, we examined the formation of MuGam-GFP foci at different concentrations of dox and found that the number of WT cells with MuGam-GFP foci increases with dox dosage, with $\sim 40 \%$ of cells having at least one MuGam-GFP focus at $400 \mathrm{ng} / \mathrm{ml}$ dox (Fig. 5b). This suggests that more breaks are induced at higher dox concentrations in WT cells. 
Unlike I-Scel or phleomycin induced DSBs, the $\triangle$ greA-mediated suppression of dox-induced DSB repair was not RecA or RecB dependent, indicating the involvement of a mechanism other than the canonical recombination DSB break repair pathway (Fig. 5c). Since spontaneous DSBs are thought to largely arise during replication stalling and have been shown to require the RuvC helicase for processing of recombination intermediates ${ }^{32}$, we tested the $\triangle r u v C$ mutant for dox-induced toxicity and found that this mutant was as sensitive to dox as the WT strain and again was not involved in the $\triangle$ greA-mediated mediated suppression (Fig. 5c).

To study whether both Gre factors act similarly in the mechanism involved in dox-induced breaks, GreA and GreB were overexpressed from plasmids in both WT and $\triangle g r e A$ backgrounds. Both Gre factors when overexpressed abrogate the resistance of the $\triangle$ greA mutant in the presence of MuGam, suggesting that breaks induced by dox interact with backtracked RNAP, similar to phleomycin-induced breaks (Fig. $5 d$ ). Interestingly, the $\triangle d k s A$ strain was approximately 100 -fold more sensitive compared with WT in the presence of MuGam even at $100 \mathrm{ng} / \mathrm{ml}$ dox. However, DksA does not appear to affect $\triangle$ greA-mediated suppression of dox-induced breaks in the presence of MuGam (Fig. 5d). Overexpression of super DksA mutants that have higher affinity for interacting with RNAP rescues WT sensitivity to dox200, reiterating that the competition between GreA and DksA for RNAP binding also influences DSB generation at high dox concentrations ${ }^{33}$ (Supplementary Fig. 1b).

The above experiments may implicate a transcription-mediated mechanism in the formation of doxinduced DSBs that is independent of the canonical HR pathway. We have previously shown that uncoupling transcription and translation in E.coli results in increased transcription-replication conflicts ${ }^{23}$. Since dox is known to affect the active ribosome it is possible that DSBs at higher dox concentrations are occurring as a result of translation and transcription uncoupling ${ }^{34}$. To look more closely at the formation of DSBs during active growth in vivo, we grew MuGam-GFP expressing WT and $\triangle$ greA microcolonies on high dose $(400 \mathrm{ng} / \mathrm{ml})$ dox-containing agar pads and performed time-lapse fluorescence microscopy to determine the appearance and level of MuGam-GFP foci in individual cells (Fig. 5e). We found that WT cells contained significantly more MuGam-GFP foci than $\triangle$ greA cells, indicating that fewer DNA breaks form in $\triangle$ greA cells. $\sim 30 \%$ of WT cells formed elongated filaments whereas $\Delta$ greA cells produced very few filaments (Fig. $5 \mathrm{~g}$ ). Cell division inhibition leading to filamentation is a classic phenotype indicative of DSB-dependent DNA damage (SOS) response ${ }^{35}$. The lower filamentation in $\Delta g r e A$ cells suggests that the SOS response in not induced, potentially because fewer DSB breaks are formed at high dox concentrations in $\triangle g r e A$ (Fig. 5f). Given that the $\triangle g r e A$ mutant is known to have more overall transcriptional arrest, and that treatment with high dose of dox would likely slow down translation, the lower rate of DSB formation in $\triangle$ greA cells may reflect better transcription-translation coupling than in WT cells under these conditions. 


\section{DISCUSSION}

Proteins in DNA replication, repair, and transcription share the same DNA template and coordination between these processes are indispensable in preventing conflicts which could result in genomic instability. Studies in E.coli have pinpointed a role of RNAP secondary channel interactors in modulating transcription conflict with replication as well as DNA repair machineries ${ }^{21,36,37}$. Here we investigate how the modulation of RNAP processivity influences DSB repair in the presence of a DNA-end binding protein, MuGam.

Our study confirms that the expression of MuGam results in reduced bacterial viability as previously observed in WT cells without induced DNA damage as well as with and I-Scel cutting and extends this effect to DSBs induced by phleomycin ${ }^{8}$. This reduced survival is thought to be a consequence of MuGam blocking RecBCD access to double-strand DNA ends (DSEs). Recent in vitro data indicates however, that MuGam does not completely block RecBCD activity but rather reduces its enzyme's processivity ${ }^{4}$. Specifically, MuGam is reported to bind DNA ends and thread and slide along DNA in vitro when propelled by RecBCD translocase activity ${ }^{4}$. When we directly examined resection in cells using XO-seq at I-Scel-induced DSBs, we found that RecB-mediated DNA resection was indeed reduced in the presence of MuGam and that in the absence of RecBCD, MuGam binding at DNA-ends appears to effectively block all other exonucleases from acting on DSEs (Fig. 3b). In the presence of MuGam, $\triangle$ recA cells also show lower degradation around the I-Scel break site, which is in striking contrast to the extensive degradation seen when MuGam is not expressed, suggesting a reduction of RecBCD processivity even in the absence of functional HR (Fig. 3d). Altogether, our data shows that MuGam inhibits break repair by reducing $\operatorname{RecBCD}$ resection in vivo, and not by just blocking DNA end access to RecBCD as previously thought. We find that DNA resection by RecBCD in the presence of MuGam can go as far as $30 \mathrm{~Kb}$ passing multiple Chi sites without promoting break repair. This suggests that in addition to processivity, MuGam may also inhibit some functions of RecBCD important for recombination, such as exonuclease polarity switching activity or RecA loading.

One key finding in our study is that the modulation of RNAP processivity influences DSB repair in the presence of MuGam. The presence of factors that rescue RNAP backtracking such as GreA and GreB increase sensitivity to MuGam (Fig. 2). Counterintuitively, the increased resistance of the $\triangle g r e A$ strain to MuGam expression after DSB induction is accompanied by an increase in DNA degradation both upstream and downstream at the DSB site (Fig. $3 f, 3 g$ ). Our in vitro transcription experiments show that following MuGam binding to DSEs, RNAP is released from the DNA in the absence of Gre factors (Fig. 4c, 4d). Based on these results, we propose a model in which loss of Gre enhances dissociation of MuGam from DSBs along with RNAP, freeing the ends for efficient repair (Fig. 4e). We further speculate that ejection of MuGam from the DNA restores RecBCD activity, promoting DNA resection and allowing 
RecA loading when RecBCD encounters a backtracked RNAP (Fig. 4e). MuGam bound to DSBs likely serves as a substantial roadblock to transcription and may be released from the DNA by RNAP when lacking factors like GreA,B as suggested by our in vitro transcription assays. Whether MuGam passively dissociates from DSEs in the absence of GreA or is actively removed in vivo is unknown. DNA curtain assays show that MuGam dissociates only after RecBCD stops translocating, suggesting that MuGam may be trapped by the advancing exonuclease ${ }^{4}$. In our model, we propose that when GreA is present, futile attempts to restart transcription adjacent to the DSB impedes MuGam removal and inhibits repair (Fig. 4e).

Dox is an antibiotic used to treat a wide variety of bacterial infections including chest, skin, dental and sexually transmitted infections. We observed that subinhibitory doses of dox is toxic to WT cells expressing MuGam. Western-blot analysis revealed that MuGam protein levels were not changed at higher doses of doxycycline, and yet DSBs occurred in a dose response manner in WT cells, as measured by MuGam-GFP foci (Fig. 5b). These results lead us to conclude that a sub-inhibitory dose of dox somehow induces DSBs, which could result in increased antibiotic resistance via stress induced mutagenesis ${ }^{38}$.

The effects of dox-induced DSBs are only revealed when MuGam is expressed, leading to a synergistic loss of survival, which is surprisingly not dependent on the canonical RecA-mediated HR pathway (Fig. $5 c)$. We show that the synergistic loss of survival is completely rescued by loss of GreA. The presence of Gre factors and co-translating ribosomes have been shown to suppress RNAP backtracking ${ }^{39}$. Since higher doses of dox are known to affect translation, and translation and transcription are coupled in bacteria, the rescue of this toxicity in $\triangle$ greA cells implicates transcription and/or backtracked RNAP in this mechanism of DSB generation. Importantly, we found that $\triangle$ greA cells have fewer DSBs compared to WT (Fig. 5e, 5f) at higher dox doses as measured by MuGam-GFP foci. A likely DNA-end target for MuGam under these conditions could be stalled replication forks ${ }^{8}$. Fewer stalled replication forks could be occurring in $\triangle g r e A$ cells due to the presence of the transcription elongation factor DksA previously shown to ameliorate transcription:translation uncoupling during amino acid starvation by releasing RNAP20,23. Therefore, in $\triangle g r e A d k s A+$ cells, the presence of DksA may release most backtracked RNAP and allow trailing ribosomes to catch up with transcription leading to better translation-transcription coupling. This new finding raises important questions about how an antibiotic targeting the ribosome may trigger DNA instability involving replication/transcription conflicts. Additional studies will be required to fully address this important issue and dissect the mechanism involved.

In a broader context, this work raises questions about the interaction between the MuGam homolog Ku and transcription at DSBs in eukaryotes. We have observed that GreA impedes DSB repair regardless of whether the DNA end is free or bound by MuGam. Perhaps similar interactions occur between TFIIS and 
$\mathrm{Ku}$ in higher organisms, reiterating the importance of understanding how transcription processivity influences DSB repair and the mechanisms that reduce conflicts and maintain genomic stability in growing cells.

\section{Acknowledgements}

We thank Susan Rosenberg for sharing strains and reagents. The study was supported by the NIH grant DP1-Al152073 (C.H) and R01- R01GM067153 (I.A). 
bioRxiv preprint doi: https://doi.org/10.1101/2022.02.08.479637; this version posted February 9, 2022. The copyright holder for this preprint (which was not certified by peer review) is the author/funder. All rights reserved. No reuse allowed without permission.

a PHL induced DSBs
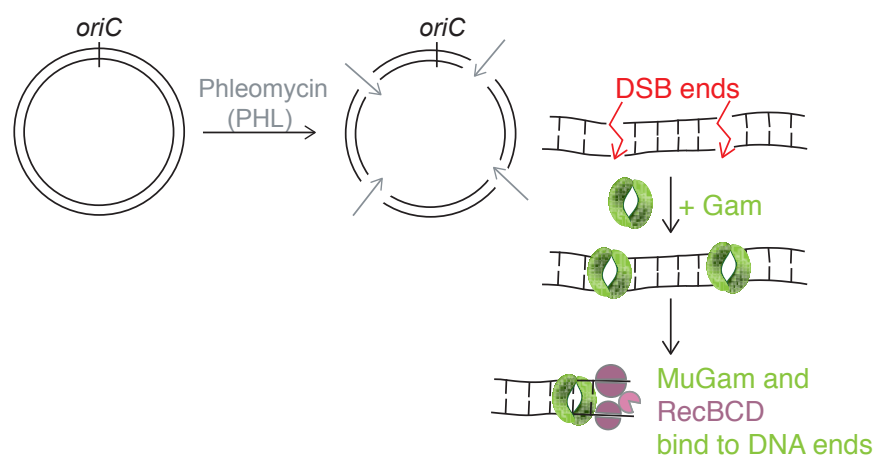

C

I-Scel induced DSB

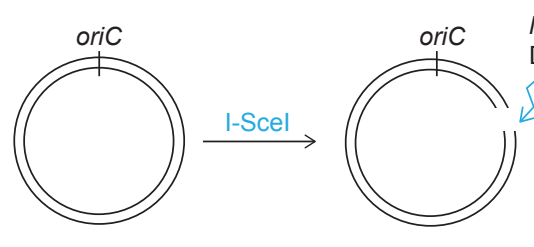

lacA

DSB end

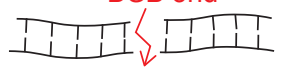

(3) $\downarrow+$ Gam

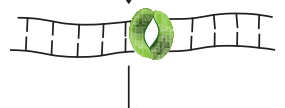

TTM MuGam and

RecBCD

bind to DNA ends

e

I-Scel induced DSB

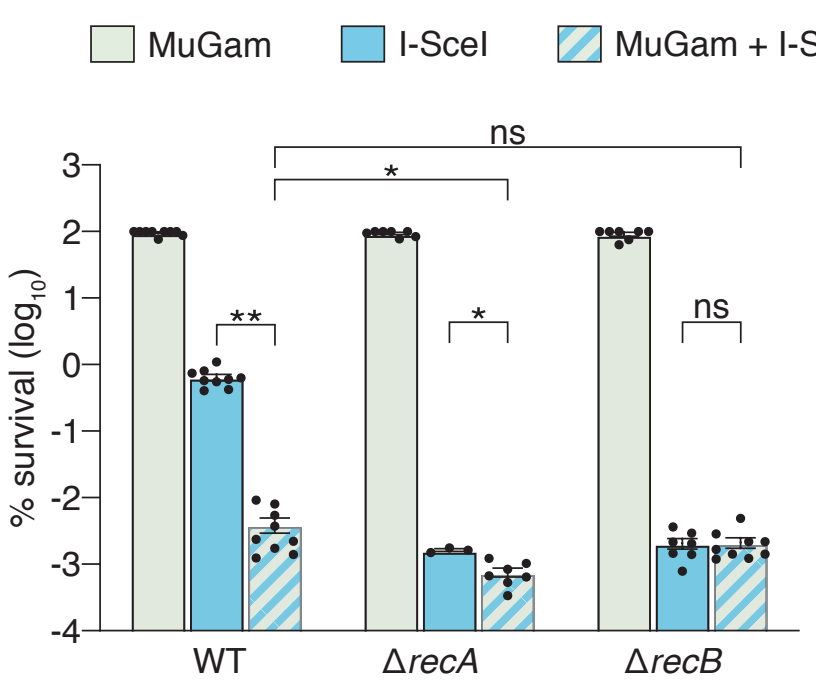

$\mathrm{PHL}$ induced DSBS

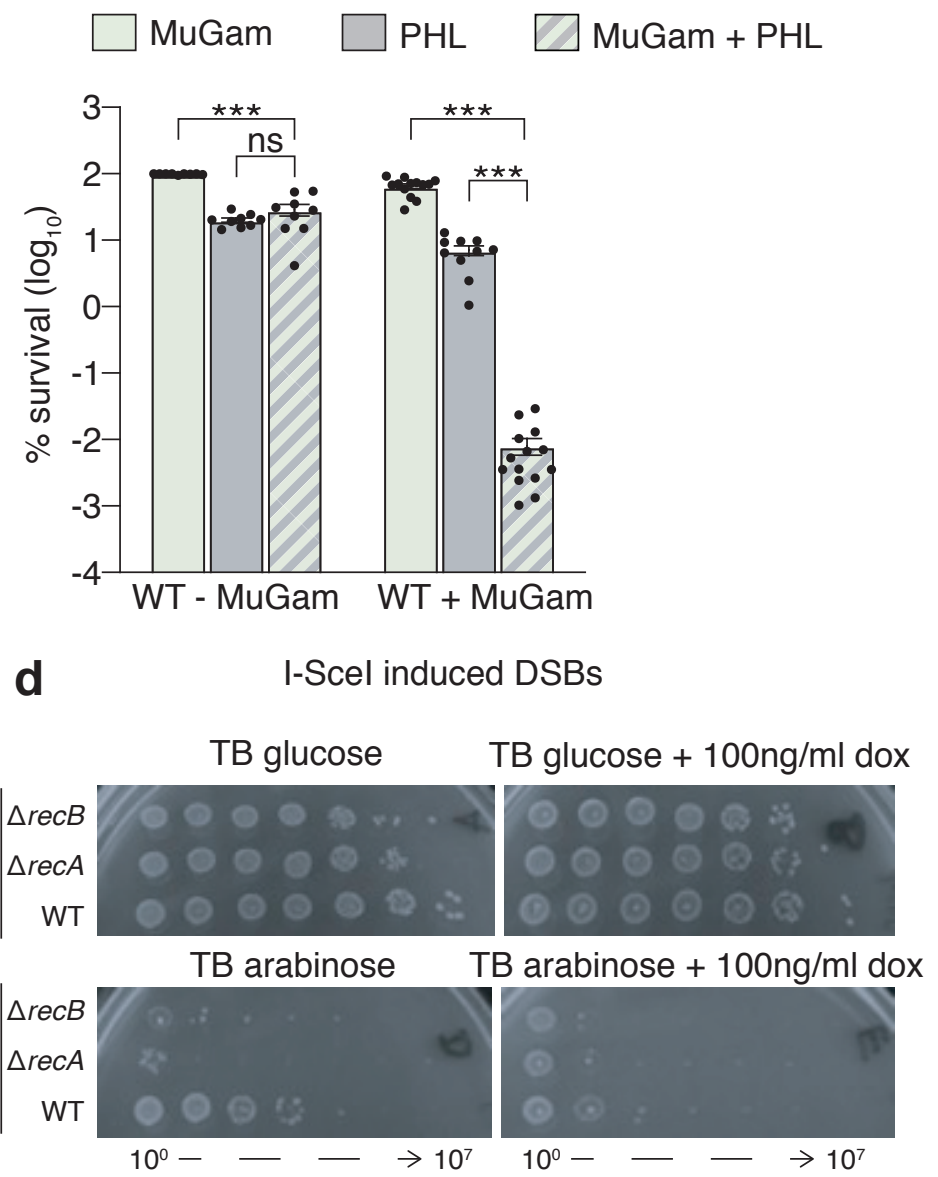


Figure 1. E. coli are sensitive to MuGam expression when DSBs are induced in vivo.

a Schematic showing phleomycin (PHL)-induced DSB bound by MuGam followed by the loading of the RecBCD complex in E. coli. b Quantitative survival of the wild-type (WT) strain treated with $1 \mu \mathrm{g} / \mathrm{ml} \mathrm{PHL}$ with or without $100 \mathrm{ng} / \mathrm{ml}$ doxycycline (dox) to induce MuGam expression, mean \pm S.E.M. ${ }^{* * *} P \leq 0.001$; ${ }^{* *} P \leq 0.01$; ${ }^{*} P \leq 0.05$; ns, $P \geq 0.05$ (Kruskal-Wallis test followed by pairwise Wilcox test with multiple testing correction). c Expression of the I-Scel enzyme creates a single DSB at lacA. d Representative viability of the indicated strains without (TB glucose $+100 \mathrm{ng} / \mathrm{ml}$ dox) and with I-Scel induced DSBs (TB arabinose $+100 \mathrm{ng} / \mathrm{ml}$ dox). e Quantitative survival of the indicated mutants with expression of MuGam $(100 \mathrm{ng} / \mathrm{ml}$ dox $)$, I-Scel induction $(0.2 \%$ arabinose) or MuGam and I-Scel $(100 \mathrm{ng} / \mathrm{ml}$ dox $+0.2 \%$ arabinose), mean \pm S.E.M. ${ }^{* * *} P \leq 0.001$; ${ }^{* *} P \leq 0.01$; ${ }^{*} P \leq 0.05$; ns, $P \geq 0.05$ (Kruskal-Wallis test followed by pairwise Wilcox test with multiple testing correction). 

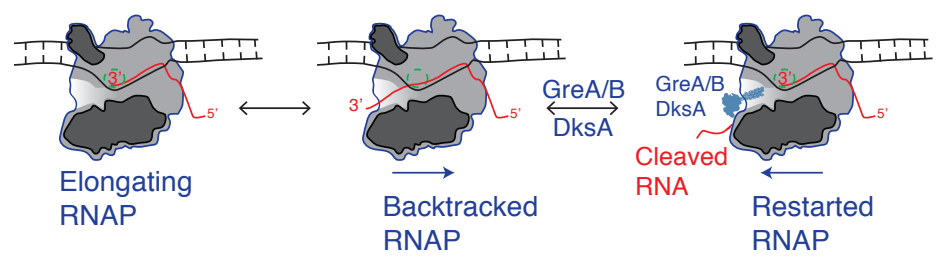

C

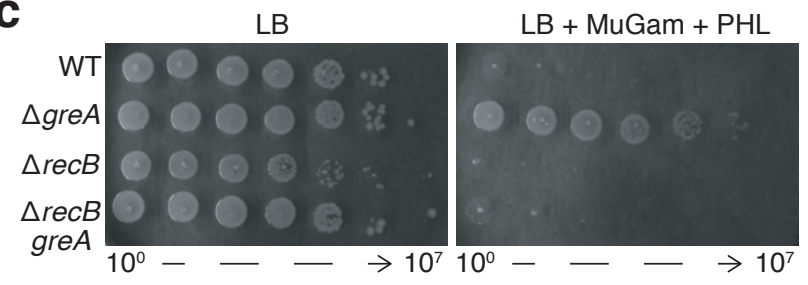

d

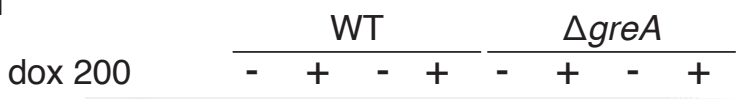

$100 \mathrm{kD}$
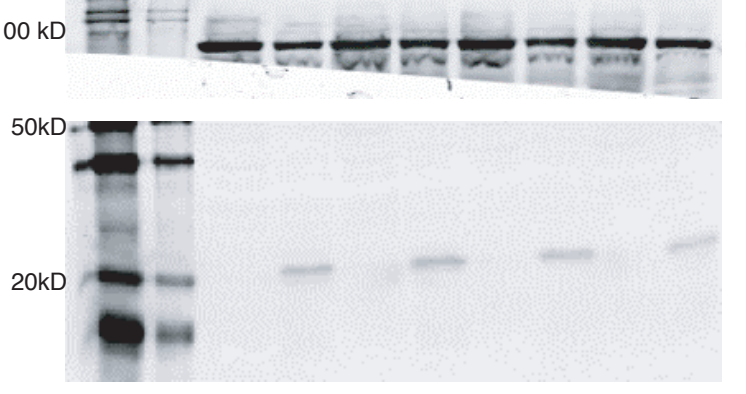

GroEL

MuGam
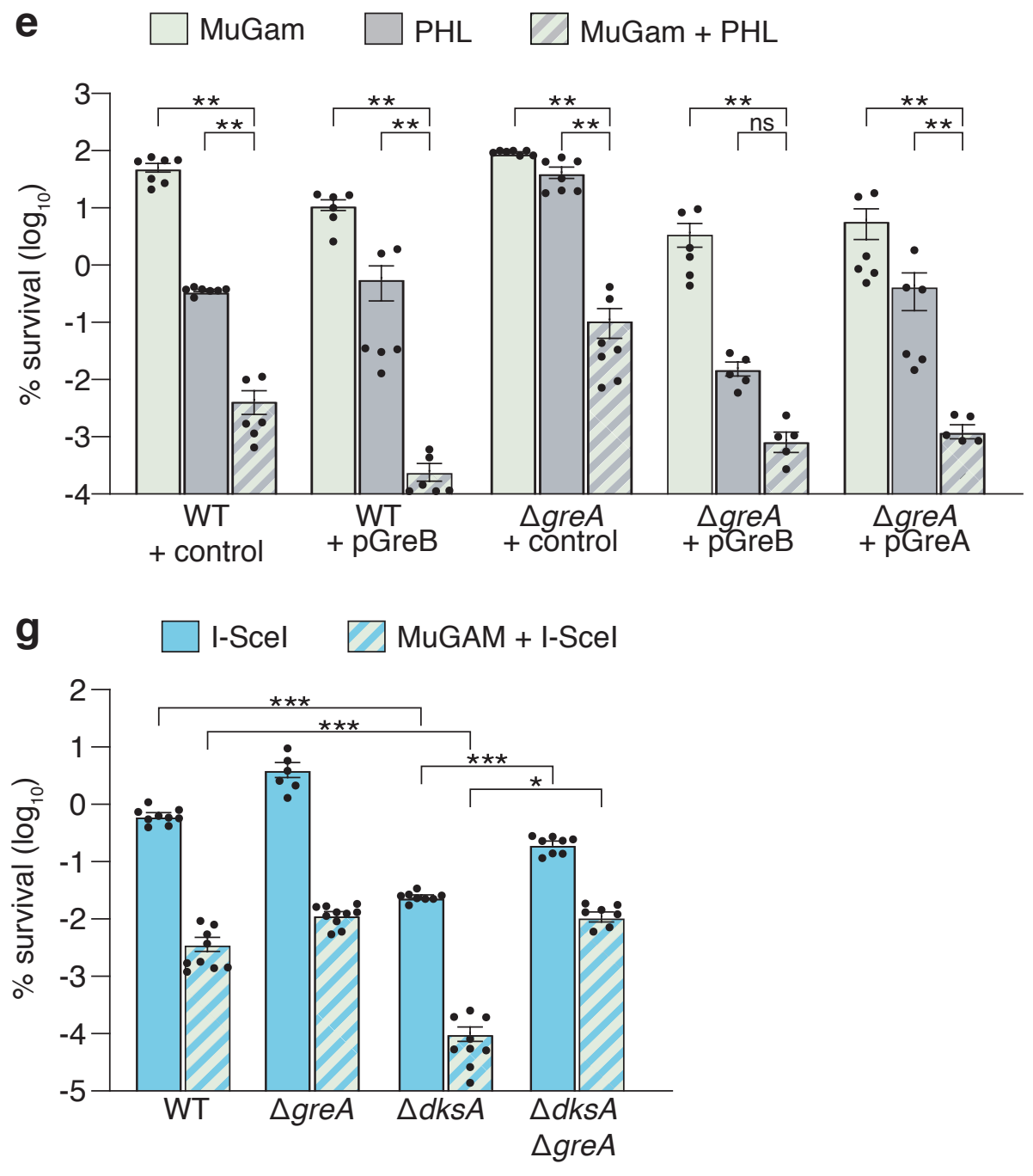

Figure 2 
Figure 2. RNAP-secondary channel interactors influence MuGam survival after DSB induction.

a Schematic showing that GreA, GreB reverse RNAP backtracking by catalyzing cleavage of RNA extruded into the secondary channel. DksA also binds to the RNAP secondary channel and can rescue backtracked RNAP without transcript cleavage. b Quantitative survival of the indicated mutants treated as in Fig. $1 \mathrm{~b}$, mean \pm S.E.M. ${ }^{* *} \mathrm{P}<0.001{ }^{* \star} P \leq 0.01$; ${ }^{\star} P \leq 0.05$; ns, $P \geq 0.05$ (Kruskal-Wallis test followed by pairwise Wilcox test with multiple testing correction). c Representative viability of the indicated strains to PHL-induced DSB with MuGam expression (100ng/ml dox) or without. d Western blot for MuGam in the induced (+dox) and un-induced (-dox) conditions using GroEL for normalization of protein levels and quantification of protein levels, (2 biological replicates) e Quantitative survival of $1 \mu \mathrm{g} / \mathrm{ml}$ PHL-induced DSB in the presence of MuGam (100ng/ml dox) after expression of control plasmid or high copy plasmid expressing either GreA or GreB with $0.1 \mathrm{mM}$ IPTG in the indicated mutants, mean \pm S.E.M. ${ }^{* *} P \leq 0.01$; ns, $P \geq 0.05$ (Kruskal-Wallis test followed by pairwise Wilcox test with multiple testing correction). $\mathbf{f , g}$ Quantitative survival of the indicated mutants as in Fig. 1e, mean \pm S.E.M. ${ }^{* * *} P \leq 0.001$; ${ }^{* *} P \leq 0.01 ;{ }^{*} P \leq$ 0.05 ; ns, $P \geq 0.05$ (Kruskal-Wallis test followed by pairwise Wilcox test with multiple testing correction). 
bioRxiv preprint doi: https://doi.org/10.1101/2022.02.08.479637; this version posted February 9, 2022. The copyright holder for this preprint

a

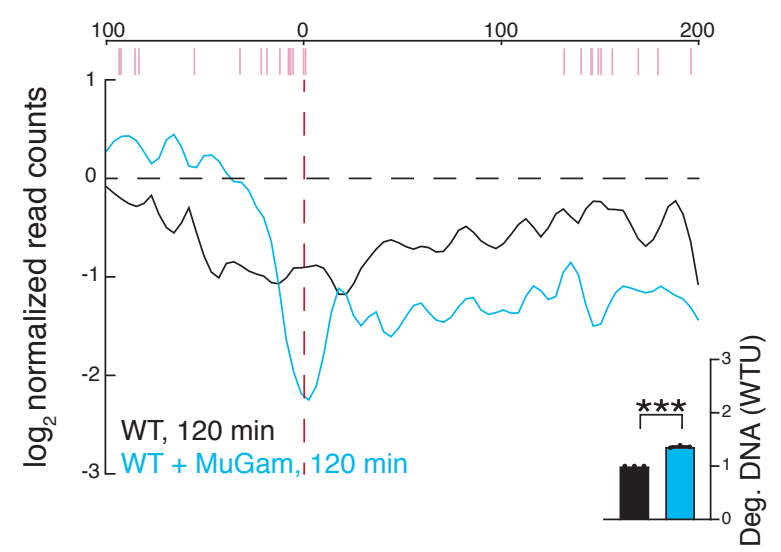

C Distance from cutsite (kb)

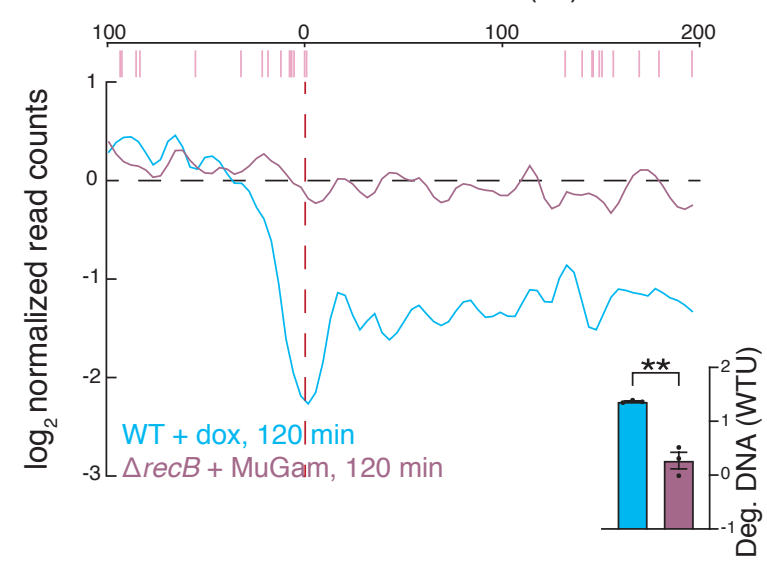

e Distance from cutsite (kb)

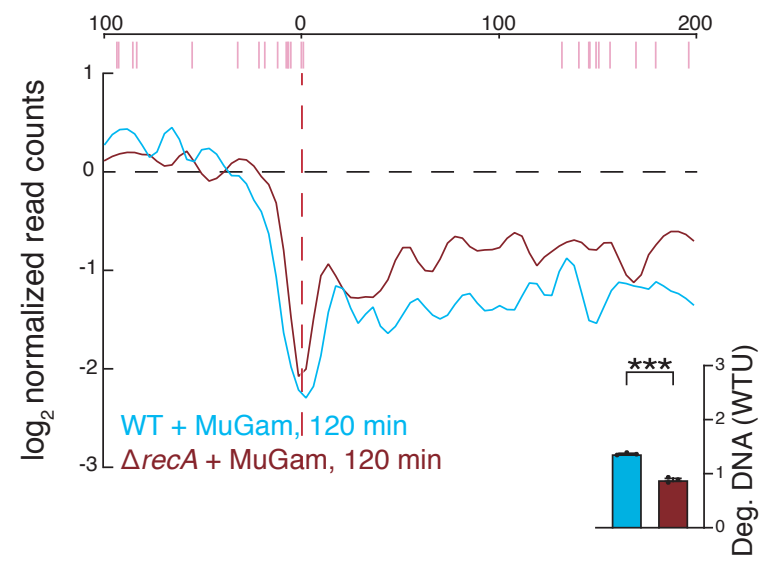

g

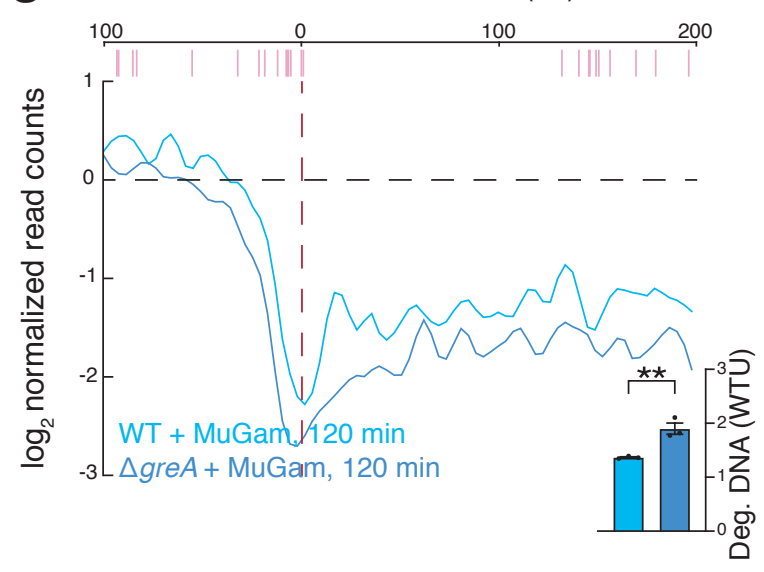

b

Distance from cutsite $(\mathrm{kb})$

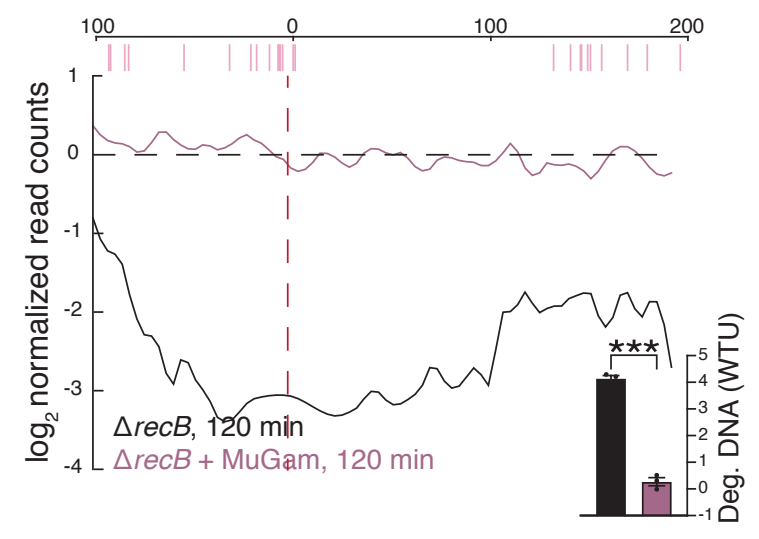

d Distance from cutsite (kb)

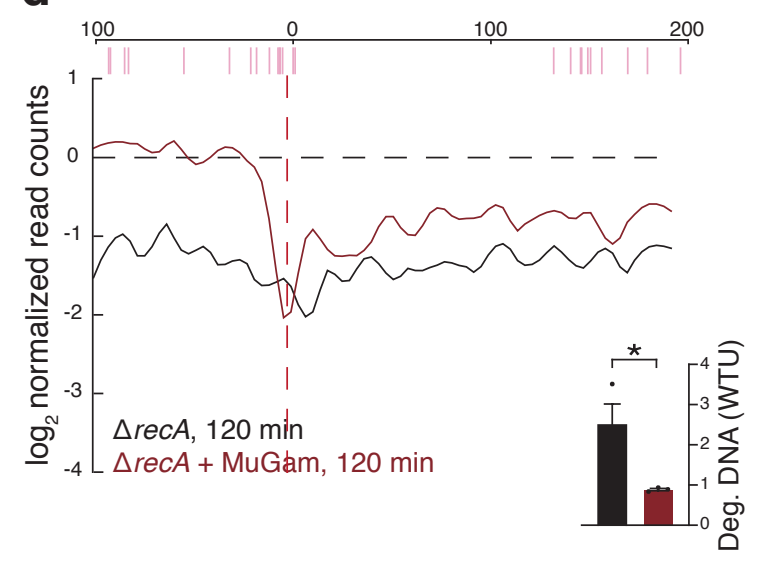

f Distance from cutsite $(k b)$

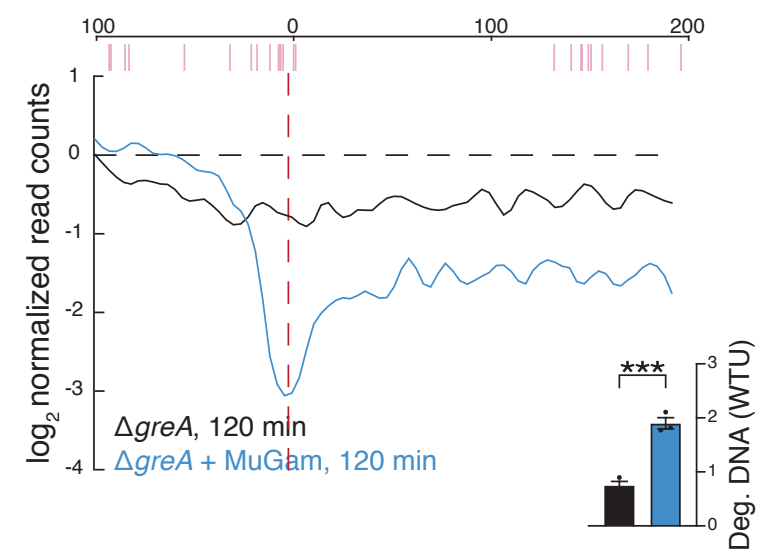


bioRxiv preprint doi: https://doi.org/10.1101/2022.02.08.479637; this version posted February 9, 2022. The copyright holder for this preprint (which was not certified by peer review) is the author/funder. All rights reserved. No reuse allowed without permission.

Figure 3. DNA degradation around the DBS site is altered by MuGam binding.

a-g XO-seq degradation in the indicated mutants without or with MuGam expression (100ng/ml dox) 120 minutes after I-Scel induced DSB induction at lacA. Red vertical line indicates position of DSB site. Pink lines show Chi site positions. Representative graph shown, bar plots are DNA degradation as measured by area under the curve, mean \pm S.E.M. ${ }^{* *} P \leq 0.001$, ${ }^{* *} P \leq 0.01, \leq 0.05$ (two-tailed two sample $t$-test). 


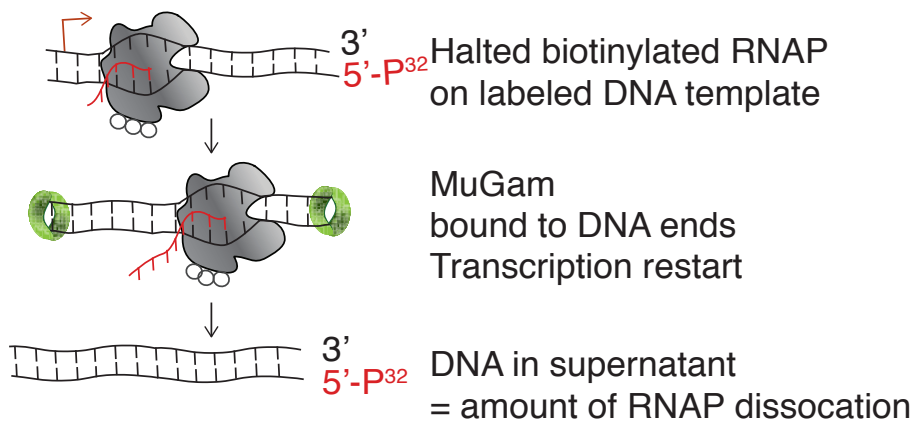

C

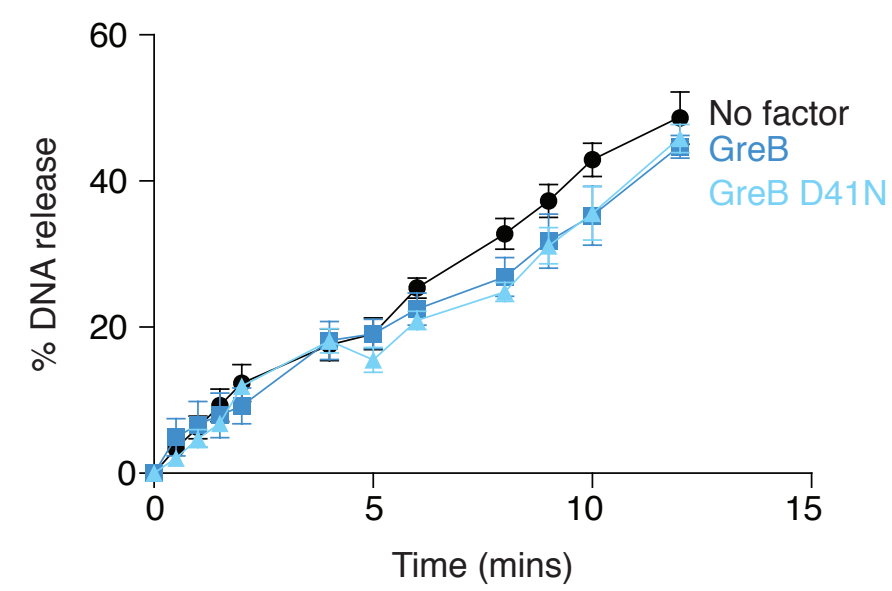

e

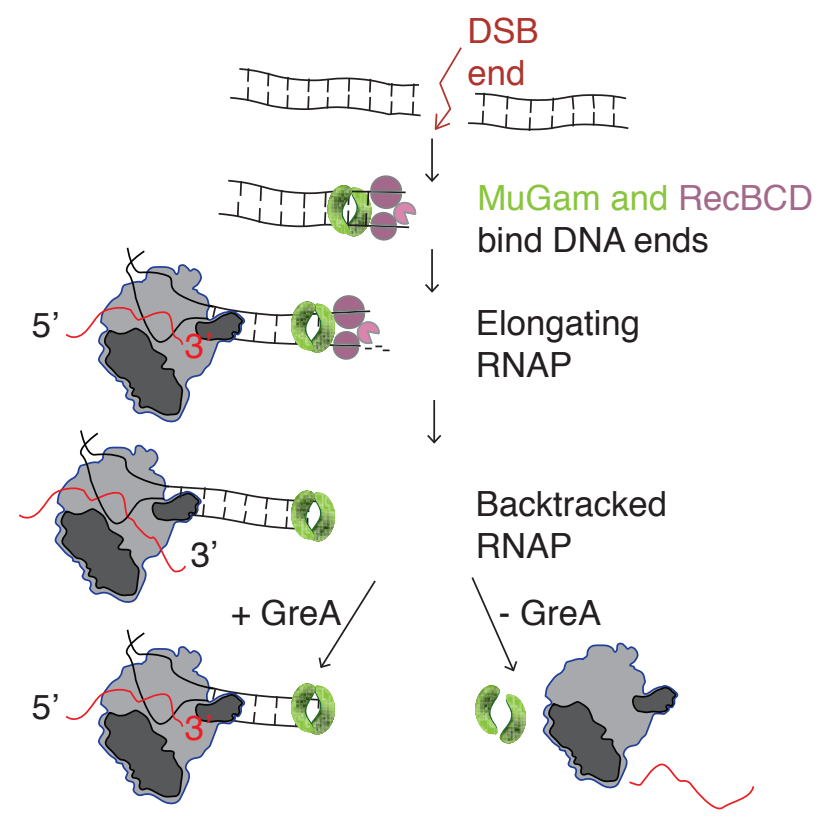

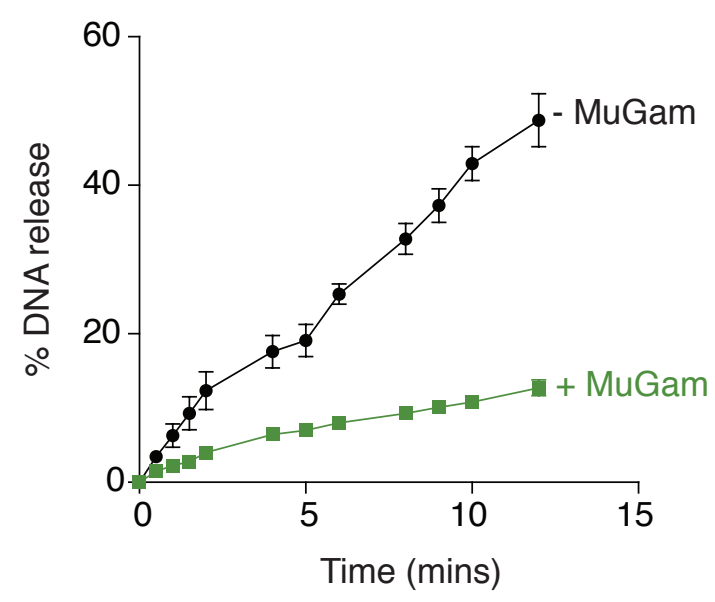

d

$$
\text { + MuGam }
$$

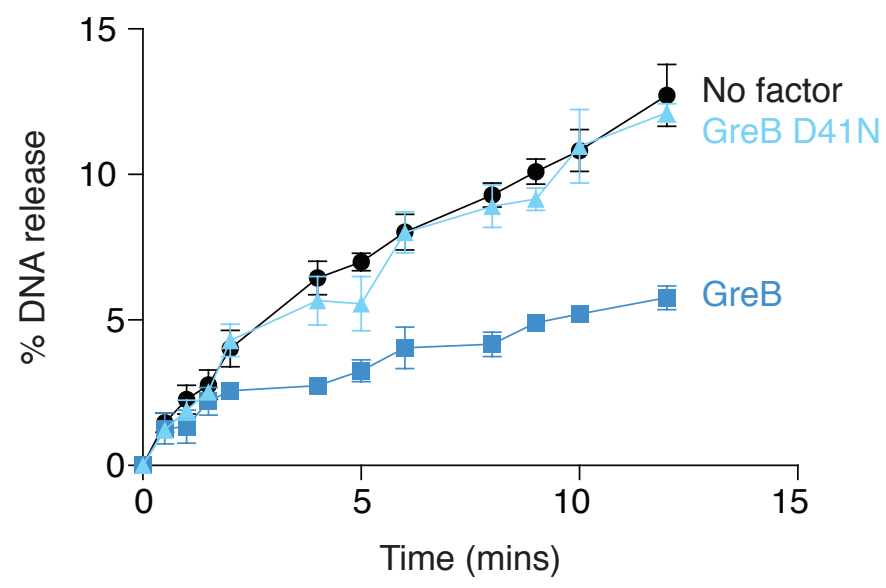


Figure 4. MuGam remains bound to the DNA end in the presence of the RNAP secondary channel interactor GreB.

a Schematic of the in vitro experiment (see methods). b-d In vitro measurements of RNAP release over time in the presence or absence of indicated factors with and without purified MuGam. e Model of RNAP, MuGam and DSB repair interaction. MuGam binds to DSB ends and slows down RecBCD resection. RNAP backtracks when it encounters a protein obstacle on the DNA (MuGam). In the presence of GreA, a futile cycle of backtracking and restart ensues, preventing DSB repair. Without GreA, RNAP and MuGam are removed from the DNA, allowing for normal DSB repair. 

(which was not certified by peer review) is the author/funder. All rightsfoserved. No reuse allowed without permission.
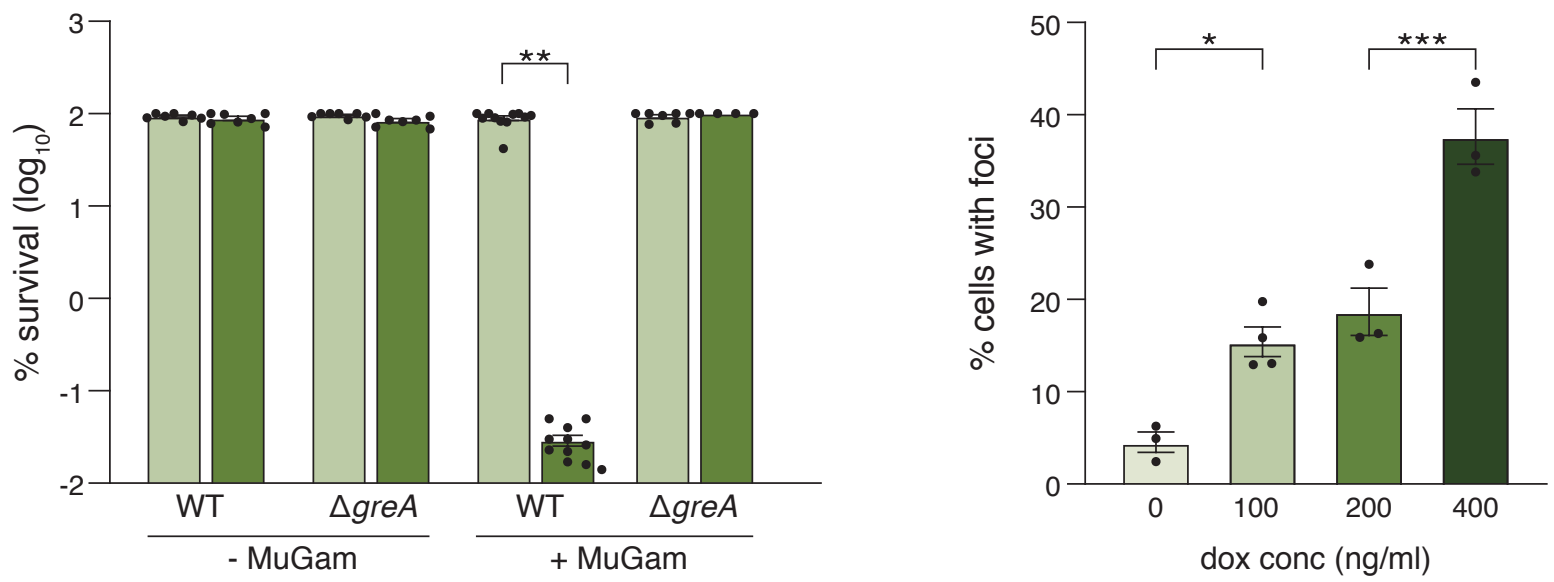

C

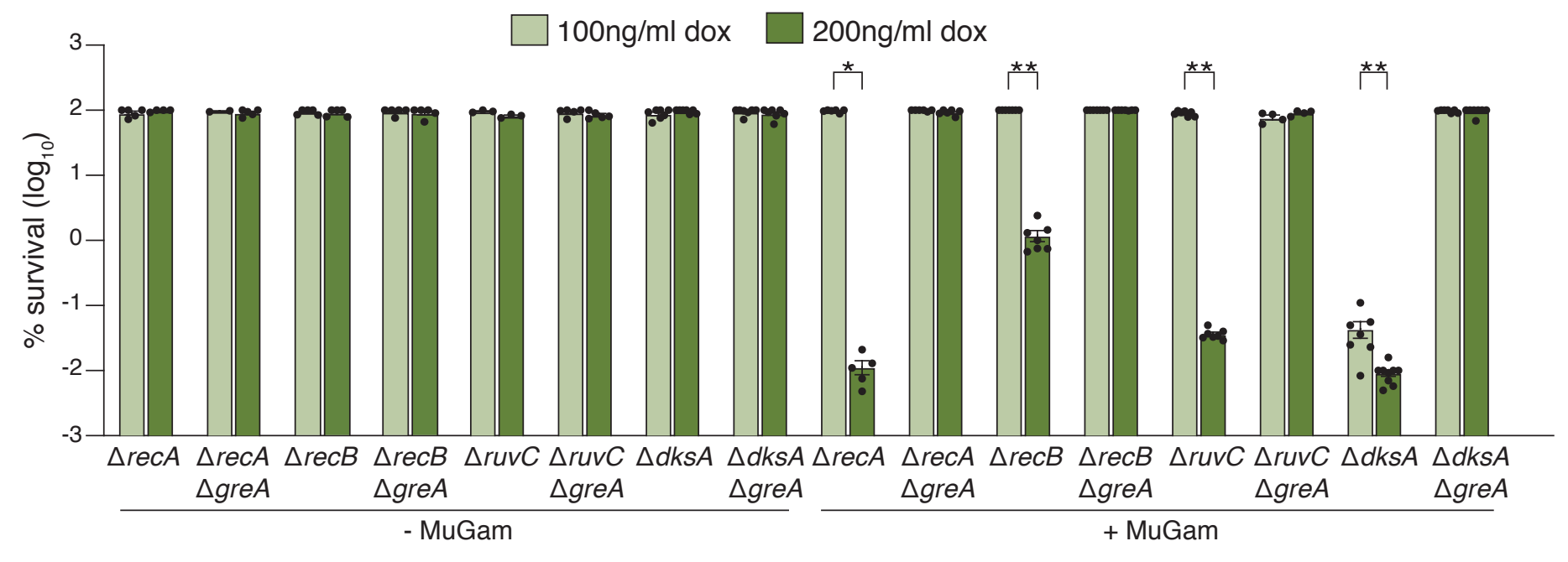

d

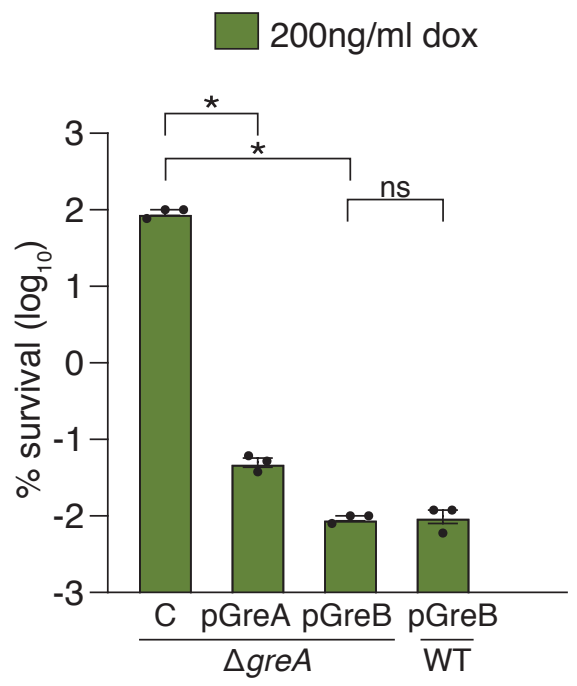

e
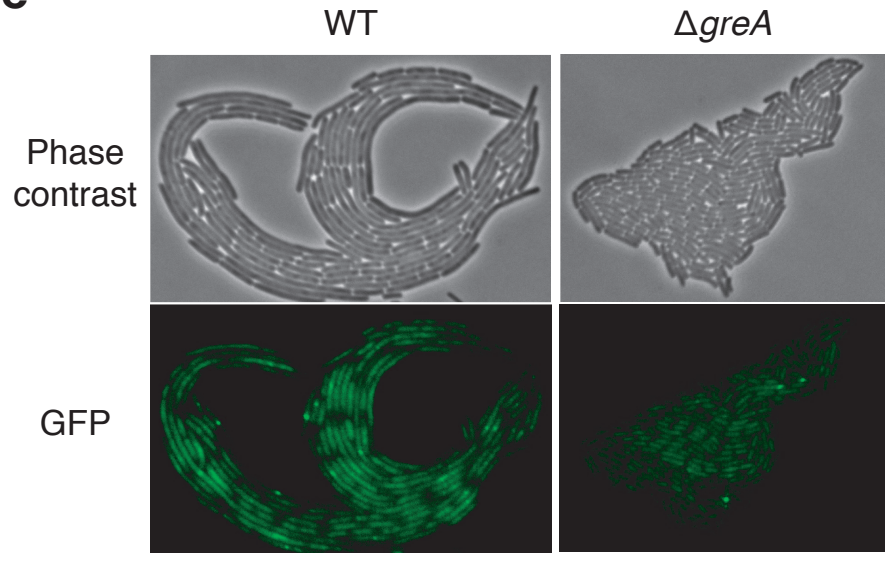

g
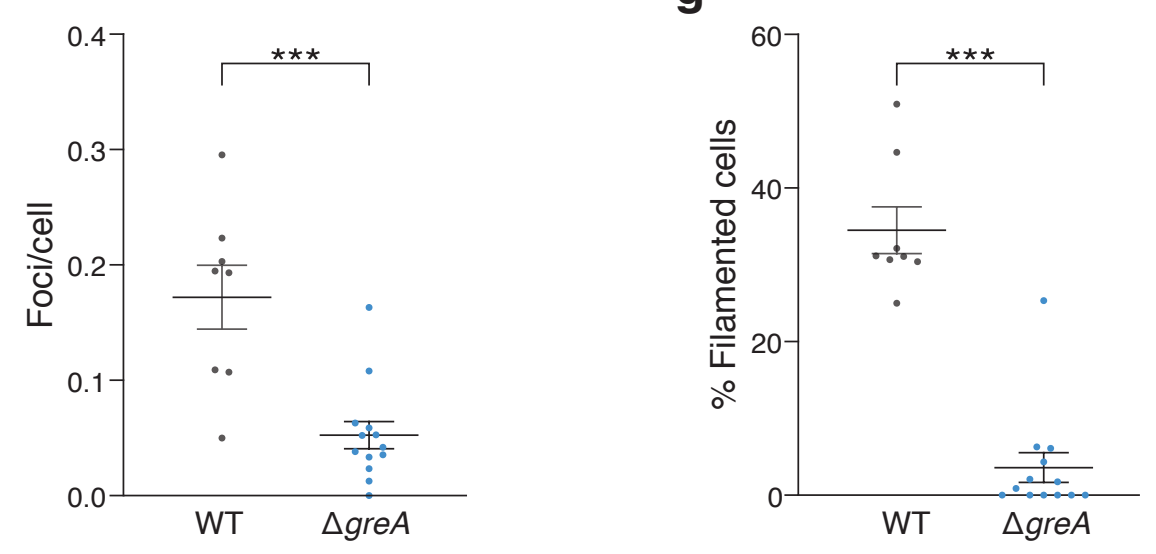
Figure 5. High dose of dox induces DSBs, that is reduced in the absence of GreA.

a Quantitative survival of WT and the $\triangle$ greA mutant strain and low $(100 \mathrm{ng} / \mathrm{ml})$ and high $(200 \mathrm{ng} / \mathrm{ml})$ dox; mean \pm S.E.M. ${ }^{* *} P \leq 0.01$ (Kruskal-Wallis test followed by pairwise Wilcox test with multiple testing correction). b Quantification of MuGam-GFP foci in WT cells grown in the presence of increasing concentrations of dox; mean \pm S.E.M. ${ }^{* * *} P \leq 0.001$, ${ }^{*} P \leq 0.05$ (One-way ANNOVA, Tukey Posthoc). c Quantitative survival of the indicated mutants at either $100 \mathrm{ng} / \mathrm{ml}$ or $200 \mathrm{ng} / \mathrm{ml}$ dox; mean \pm S.E.M. ${ }^{* \star} P \leq$ $0.01,{ }^{*} P \leq 0.05$ (Kruskal-Wallis test followed by pairwise Wilcox test with multiple testing correction). d Quantitative survival after expression of control plasmid (c) or high copy plasmid expressing either GreA or GreB (0.1mM IPTG induction) in the indicated mutants, mean \pm S.E.M. ${ }^{*} P \leq 0.05$. e Bright-field and GFP images of actively growing WT and $\triangle$ greA microcolonies on agar pads containing $400 \mathrm{ng} / \mathrm{ml}$ dox followed by time-lapse microscopy. g,f Percentage of filamented cells (>6uM) and quantification of MuGam-GFP foci from e; $\mathrm{n} \geq 3$ microcolonies (dots represent individual microcolonies analyzed), mean \pm S.E.M. ${ }^{* * * *} \mathrm{P}<0.0001,{ }^{* * *} \mathrm{P}=0.0002$ (unpaired t-test). 
bioRxiv preprint doi: https://doi.org/10.1101/2022.02.08.479637; this version posted February 9, 2022. The copyright holder for this preprint

a (which was not certified by peer review) is the author/funder. All rights reserved. No reuse allowed without permission. I-Scel +

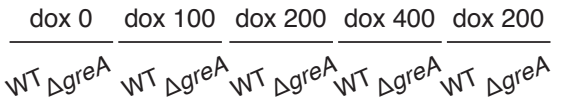

$100 \mathrm{kD}$
$75 \mathrm{kD}$

$50 \mathrm{kD}$

$37 \mathrm{kD}$

$25 \mathrm{kD}$

$20 \mathrm{kD}$

$15 \mathrm{kD}$

MuGam

GroEL

b

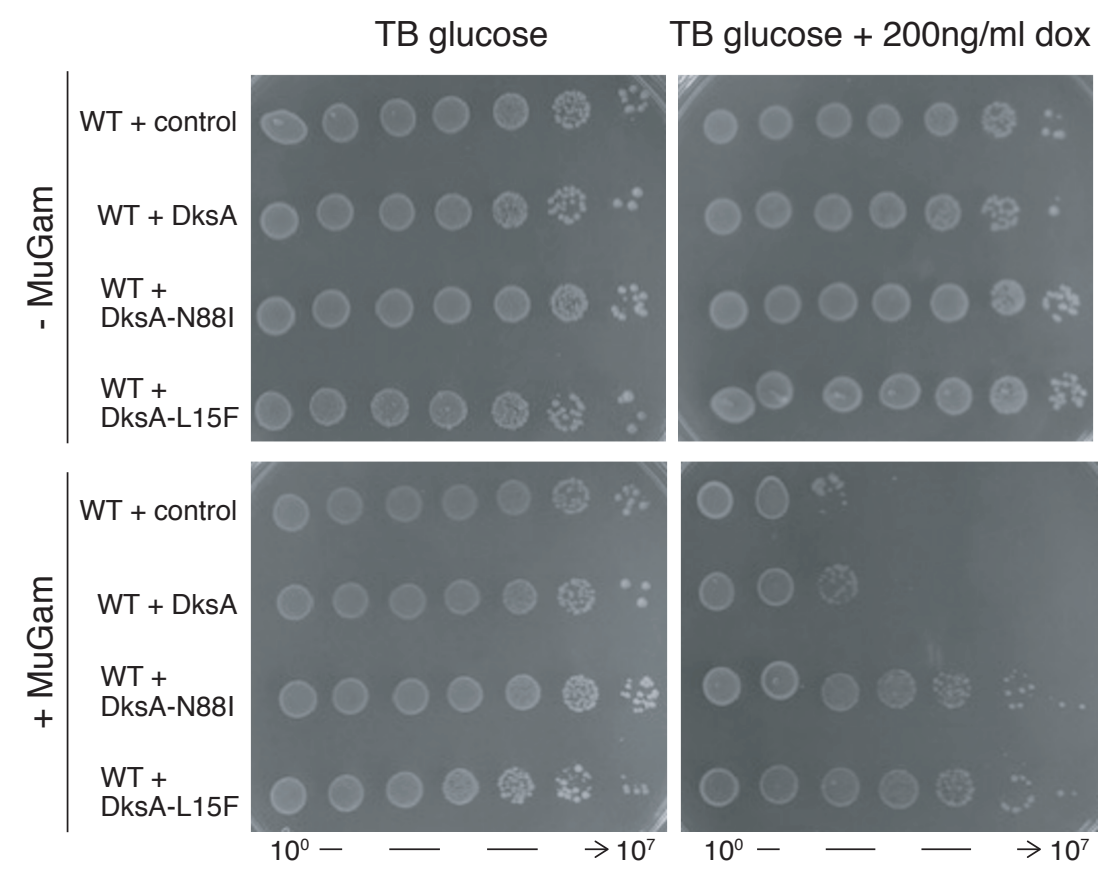

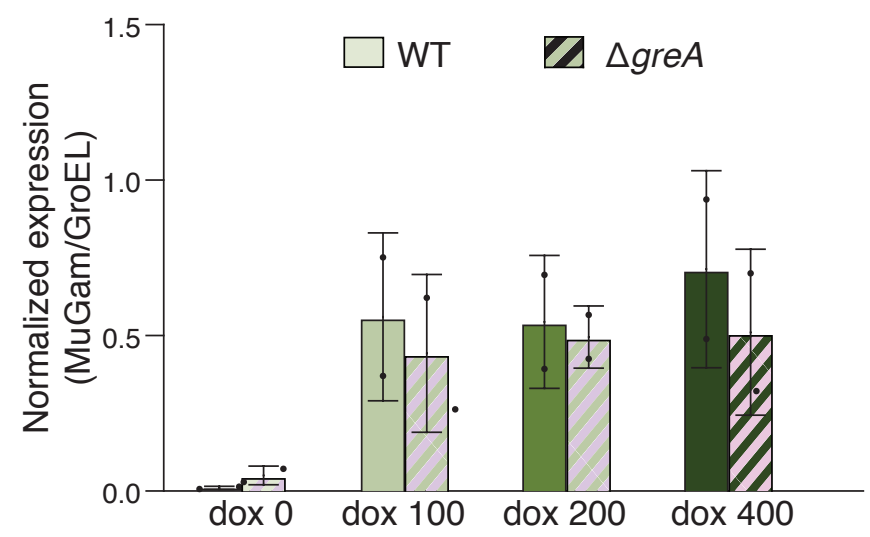


Supplementary Figure 1. Higher doses of dox does not increase MuGam protein levels but survival is rescued by overexpression of super DksA mutants

a Quantification of Western blot for MuGam after incubation of WT and $\Delta g r e A$ cells with $0,100,200$, and $400 \mathrm{ng} / \mathrm{ml}$ dox using GroEL for normalization of and quantification of normalized protein levels, mean \pm S.E.M. b Semiquantitative survival assays in strains with or without MuGam (dox 200ng/ml) containing control plasmid or plasmids overexpressing super DksA mutants (N88I and L15F) (0.1mMIPTG). 


\section{References}

1 Featherstone, C. \& Jackson, S. P. DNA double-strand break repair. Curr Biol 9, R759761, doi:10.1016/S0960-9822(00)80005-6 (1999).

2 Wilson, T. E., Topper, L. M. \& Palmbos, P. L. Non-homologous end-joining: bacteria join the chromosome breakdance. Trends Biochem Sci 28, 62-66, doi:10.1016/S09680004(03)00005-7 (2003).

3 Chayot, R., Montagne, B., Mazel, D. \& Ricchetti, M. An end-joining repair mechanism in Escherichia coli. Proc Natl Acad Sci $U$ S A 107, 2141-2146, doi:10.1073/pnas.0906355107 (2010).

4 Bhattacharyya, S. et al. Phage Mu Gam protein promotes NHEJ in concert with. Proc Natl Acad Sci U S A 115, E11614-E11622, doi:10.1073/pnas.1816606115 (2018).

5 d'Adda di Fagagna, F., Weller, G. R., Doherty, A. J. \& Jackson, S. P. The Gam protein of bacteriophage $\mathrm{Mu}$ is an orthologue of eukaryotic $\mathrm{Ku}$. EMBO Rep 4, 47-52, doi:10.1038/sj.embor.embor709 (2003).

6 Williams, J. G. \& Radding, C. M. Partial purification and properties of an exonuclease inhibitor induced by bacteriophage Mu-1. J Virol 39, 548-558, doi:10.1128/JVI.39.2.548558.1981 (1981).

7 Abraham, Z. H. \& Symonds, N. Purification of overexpressed gam gene protein from bacteriophage $\mathrm{Mu}$ by denaturation-renaturation techniques and a study of its DNAbinding properties. Biochem J 269, 679-684, doi:10.1042/bj2690679 (1990).

8 Shee, C. et al. Engineered proteins detect spontaneous DNA breakage in human and bacterial cells. Elife 2, e01222, doi:10.7554/eLife.01222 (2013).

9 Cui, L. \& Bikard, D. Consequences of Cas9 cleavage in the chromosome of Escherichia coli. Nucleic Acids Res 44, 4243-4251, doi:10.1093/nar/gkw223 (2016).

10 Akroyd, J. \& Symonds, N. Localization of the gam gene of bacteriophage mu and characterisation of the gene product. Gene 49, 273-282, doi:10.1016/03781119(86)90288-x (1986).

11 Taylor, A. F. \& Smith, G. R. Substrate specificity of the DNA unwinding activity of the RecBC enzyme of Escherichia coli. J Mol Biol 185, 431-443, doi:10.1016/00222836(85)90414-0 (1985).

12 Dillingham, M. S. \& Kowalczykowski, S. C. RecBCD enzyme and the repair of doublestranded DNA breaks. Microbiol Mol Biol Rev 72, 642-671, Table of Contents, doi:10.1128/MMBR.00020-08 (2008). 
13 Shanbhag, N. M., Rafalska-Metcalf, I. U., Balane-Bolivar, C., Janicki, S. M. \& Greenberg, R. A. ATM-dependent chromatin changes silence transcription in cis to DNA double-strand breaks. Cell 141, 970-981, doi:10.1016/j.cell.2010.04.038 (2010).

14 Pani, B. \& Nudler, E. Mechanistic insights into transcription coupled DNA repair. DNA Repair (Amst) 56, 42-50, doi:10.1016/j.dnarep.2017.06.006 (2017).

15 Park, J. S., Marr, M. T. \& Roberts, J. W. E. coli Transcription repair coupling factor (Mfd protein) rescues arrested complexes by promoting forward translocation. Cell 109, 757767, doi:10.1016/s0092-8674(02)00769-9 (2002).

16 Kamarthapu, V. et al. ppGpp couples transcription to DNA repair in E. coli. Science $\mathbf{3 5 2 ,}$ 993-996, doi:10.1126/science.aad6945 (2016).

17 Komissarova, N. \& Kashlev, M. Transcriptional arrest: Escherichia coli RNA polymerase translocates backward, leaving the $3^{\prime}$ end of the RNA intact and extruded. Proc Natl Acad Sci U S A 94, 1755-1760, doi:10.1073/pnas.94.5.1755 (1997).

18 Borukhov, S., Sagitov, V. \& Goldfarb, A. Transcript cleavage factors from E. coli. Cell 72, 459-466, doi:10.1016/0092-8674(93)90121-6 (1993).

19 Paul, B. J. et al. DksA: a critical component of the transcription initiation machinery that potentiates the regulation of rRNA promoters by ppGpp and the initiating NTP. Cell 118, 311-322, doi:10.1016/j.cell.2004.07.009 (2004).

20 Tehranchi, A. K. et al. The transcription factor DksA prevents conflicts between DNA replication and transcription machinery. Cell 141, 595-605, doi:10.1016/j.cell.2010.03.036 (2010).

21 Myka, K. K. \& Gottesman, M. E. DksA and DNA double-strand break repair. Curr Genet 65, 1297-1300, doi:10.1007/s00294-019-00983-x (2019).

22 Sivaramakrishnan, P. et al. The transcription fidelity factor GreA impedes DNA break repair. Nature 550, 214-218, doi:10.1038/nature23907 (2017).

23 Zhang, Y. et al. DksA guards elongating RNA polymerase against ribosome-stallinginduced arrest. Mol Cell 53, 766-778, doi:10.1016/j.molcel.2014.02.005 (2014).

24 Myka, K. K., Küsters, K., Washburn, R. \& Gottesman, M. E. DksA-RNA polymerase interactions support new origin formation and DNA repair in Escherichia coli. Mol Microbiol 111, 1382-1397, doi:10.1111/mmi.14227 (2019).

25 Miller, J. H. A Short Course in Bacterial Genetics: A Laboratory Manual and Handbook for Escherichia Coli and Related Bacteria. (Cold Spring Harbor Labs Press, 1992).

26 Sambrook, J. \& Russell. Molecular Cloning: A Laboratory Manual., (CSHL Press, 2001). 
27 Holzinger, A., Phillips, K. S. \& Weaver, T. E. Single-step purification/solubilization of recombinant proteins: application to surfactant protein B. Biotechniques 20, 804-806, 808, doi:10.2144/96205bm16 (1996).

28 Laptenko, O., Lee, J., Lomakin, I. \& Borukhov, S. Transcript cleavage factors GreA and GreB act as transient catalytic components of RNA polymerase. EMBO J 22, 6322-6334, doi:10.1093/emboj/cdg610 (2003).

29 Opalka, N. et al. Structure and function of the transcription elongation factor GreB bound to bacterial RNA polymerase. Cell 114, 335-345, doi:10.1016/s0092-8674(03)00600-7 (2003).

30 Borukhov, S., Polyakov, A., Nikiforov, V. \& Goldfarb, A. GreA protein: a transcription elongation factor from Escherichia coli. Proc Natl Acad Sci U S A 89, 8899-8902, doi:10.1073/pnas.89.19.8899 (1992).

31 Anderson, D. G. \& Kowalczykowski, S. C. The translocating RecBCD enzyme stimulates recombination by directing RecA protein onto ssDNA in a chi-regulated manner. Cell $\mathbf{9 0}$, 77-86, doi:10.1016/s0092-8674(00)80315-3 (1997).

32 Gupta, S., Yeeles, J. T. \& Marians, K. J. Regression of replication forks stalled by leading-strand template damage: I. Both RecG and RuvAB catalyze regression, but RuvC cleaves the holliday junctions formed by RecG preferentially. J Biol Chem 289, 28376-28387, doi:10.1074/jbc.M114.587881 (2014).

33 Blankschien, M. D. et al. Super DksAs: substitutions in DksA enhancing its effects on transcription initiation. EMBO J 28, 1720-1731, doi:10.1038/emboj.2009.126 (2009).

34 Stevenson-Jones, F., Woodgate, J., Castro-Roa, D. \& Zenkin, N. Ribosome reactivates transcription by physically pushing RNA polymerase out of transcription arrest. Proc Natl Acad Sci U S A 117, 8462-8467, doi:10.1073/pnas.1919985117 (2020).

35 Darmon, E., Eykelenboom, J. K., Lopez-Vernaza, M. A., White, M. A. \& Leach, D. R. Repair on the go: E. coli maintains a high proliferation rate while repairing a chronic DNA double-strand break. PLoS One 9, e110784, doi:10.1371/journal.pone.0110784 (2014).

36 Dutta, D., Shatalin, K., Epshtein, V., Gottesman, M. E. \& Nudler, E. Linking RNA polymerase backtracking to genome instability in E. coli. Cell 146, 533-543, doi:10.1016/j.cell.2011.07.034 (2011).

37 Sivaramakrishnan, P., Gordon, A. J. E., Halliday, J. A. \& Herman, C. How Acts of Infidelity Promote DNA Break Repair: Collision and Collusion Between DNA Repair and Transcription. Bioessays 40, e1800045, doi:10.1002/bies.201800045 (2018). 
38 Pribis, J. P. et al. Gamblers: An Antibiotic-Induced Evolvable Cell Subpopulation Differentiated by Reactive-Oxygen-Induced General Stress Response. Mol Cell 74, 785800.e787, doi:10.1016/j.molcel.2019.02.037 (2019).

39 Proshkin, S., Rahmouni, A. R., Mironov, A. \& Nudler, E. Cooperation between translating ribosomes and RNA polymerase in transcription elongation. Science 328, 504-508, doi:10.1126/science.1184939 (2010). 